\title{
Tyrphostin AG1478 suppresses proliferation and invasion of human breast cancer cells
}

\author{
YUN-GANG ZHANG ${ }^{1,2}$, QIANG DU ${ }^{1}$, WEI-GANG FANG ${ }^{1}$, MU-LAN JIN ${ }^{2}$ and XIN-XIA TIAN ${ }^{1}$ \\ ${ }^{1}$ Department of Pathology, Peking University Health Science Center, Beijing 100083; \\ ${ }^{2}$ Department of Pathology, Beijing Chao-Yang Hospital, Capital Medical University, Beijing 100020, P.R. China
}

Received March 24, 2008; Accepted May 15, 2008

DOI: 10.3892/ijo_00000045

\begin{abstract}
Inhibition of epidermal growth factor receptor (EGFR) signaling is a promising treatment strategy for malignant tumors. In this study, we evaluated the effectiveness of Tyrphostin AG1478, a potent and specific inhibitor of EGFR tyrosine kinase, on the growth, apoptosis and invasion of breast cancer cells. Western blotting demonstrated that AG1478 inhibited the phosphorylation of EGFR, ERK1/2 and AKT in a dose-dependent manner. Three proliferation analyses, MTT, cell counting, and clone formation assay, consistently showed that AG1478 significantly inhibited cell proliferation in a dose-dependent manner. FACS analysis demonstrated that AG1478 promoted cell apoptosis. In addition, TRAP assay exhibited that AG1478 significantly suppressed telomerase activity of tumor cells, which was parallel with growth inhibition. Semi-qantitative RT-PCR revealed that the suppression of telomerase activity was correlated with the decreased expression of human telomerase catalytic subunit (hTERT) mRNA, the rate-limiting determinant of its enzyme activity. These data suggest that AG1478 suppressed cellular growth by inhibiting cellular proliferation, inducing apoptosis and inhibiting telomerase activity. Furthermore, we also examined the effects of AG1478 on cellular invasion. Boyden chamber invasion assay showed that AG1478 significantly inhibited cell invasion in a dose-dependent manner. Western blotting revealed that AG1478 could down-regulate the expression of MMP-9, which may be one of the mechanisms by which AG1478 suppressed cellular invasion. In conclusion, this study demonstrated that Tyrphostin AG1478 effectively inhibited the proliferation and invasion of breast cancer cells. Tyrphostin AG1478 may be a potential EGFR-targeted therapeutic agent for breast cancer.
\end{abstract}

Correspondence to: Dr Xin-Xia Tian, Department of Pathology, Peking University Health Science Center, Beijing 100083, P.R. China E-mail: tianxinxia@yahoo.com

Key words: breast cancer, epidermal growth factor receptor, Tyrphostin AG1478

\section{Introduction}

EGFR is widely expressed in most cell types with the exception of hematopoietic cells (1). EGFR activation is important in normal cellular processes. However, aberrantly enhanced EGFR signaling is closely associated with the development and progression of a variety of malignant tumors including breast cancer $(1,2)$. Overexpression or mutation of EGFR is often correlated with advanced tumor stages, metastasis, and poor clinical outcome of malignant tumors (3). Therefore, EGFR has become a promising molecular target for development of novel and effective anticancer agents.

Two predominant classes of EGFR inhibitors, antiEGFR monoclonal antibodies and tyrosine kinase inhibitors, have been developed (4-6). Anti-EGFR antibodies such as cetuximab, panitumumab, matuzumab, MDX-447, nimutozumab, and mAb806, bind to the extracellular domain of the receptor and compete with ligand binding $(5,7)$. EGFR selective tyrosine kinase inhibitors (TKIs) such as erlotinib, gefitinib, EKB-569, lapatinib (GW572016), PKI-166, and canertinib (CI-1033), target the adenosine triphosphate (ATP) binding site on the intracellular kinase domain and prevent tyrosin kinase activation $(6,7)$. These agents have been studied for the treatment of colorectal, lung, breast, pancreatic, renal, head and neck, gynecologic, and prostate cancer $(1,6,7)$. However, only a few of EGFR-targeted agents have been approved by FDA, such as cetuximab and panitumumab for the treatment of metastatic colorectal cancer, cetuximab for head and neck cancer, gefitinib for the treatment of refractive non-small cell lung cancer, erlotinib for advanced/metastatic lung cancer, erlotinib in combination with gemcitabine for advanced/metastatic pancreatic cancer treatment (8).

Many studies on EGFR-targeted therapy in breast cancer have been performed. It has been demonstrated that inhibitors of the EGFR-signaling can abrogate or delay the emergence of anti-estrogen resistance or antiHER2 resistance in breast cancer $(9,10)$. However, relative to HER2-targeted therapy with trastuzumab, studies of EGFR inhibitors in breast cancer are still in their infancy. The large part of research in this area has been focused on gefitinib. Selected published data from phase II studies failed to show that gefitinib has a significant disease control rate in heavily pre-treated metastatic breast cancer [11,12; Albain et al, Breast Cancer Res Treat 76 (Suppl. 1): abs. 20, 2002). 
To date, no randomized controlled phase III trials have been reported involving EGFR signal transduction inhibitors in breast cancer. Searching for EGFR-targeted novel agents is an important and active research issue.

AG1478, a specific inhibitor of EGFR tyrosine kinase, has been mainly used for laboratory research before. There is increasing evidence to suggest that AG1478 has anti-tumor activity. AG1478 has significant anti-proliferative effects both in in vitro cell models and in vivo mouse xenograft models (13-18). AG1478 also enhances anti-tumor efficacy of cytotoxic drugs and the monoclonal antibody 806, an anti-EGFR antibody, in some tumor cells $(19,20)$. However, the direct effects of the Tyrphostin AG1478 on breast cancer cells remain to be elucidated. In this study, we investigated the effectiveness of Tyrphostin AG1478 on the growth, apoptosis and invasion of breast cancer cells.

\section{Materials and methods}

Cell culture. The human breast cancer cell lines MDA-MB231 and MCF-7 were obtained from American Type Culture Collection (Rockville, MD). Cells were grow in RPMI-1640 supplemented with $10 \%$ FBS (Gibco), $100 \mathrm{U} / \mathrm{ml}$ penicillin and $100 \mu \mathrm{g} / \mathrm{ml}$ streptomycin (North China Pharmaceutical Factory), in a humidified atmosphere of $5 \% \mathrm{CO}_{2}$ at $37^{\circ} \mathrm{C}$.

Treatment with Tyrphostin AG 1478. The selective EGFR blocker Tyrphostin AG1478 (Sigma Chemical Co., St. Louis, MO) was dissolved in DMSO (Sigma) for preparation of $10 \mathrm{mM}$ stock. For the experiments, the tyrphostin was diluted with RPMI-1640 containing 10\% FBS. MDA-MB231 and MCF-7 cells were treated with serial concentrations of Tyrphostin AG1478. DMSO (0.1\%) was used as a control.

Cell growth assay. The antiproliferative effect of Tyrphostin AG1478 on breast cancer cells was evaluated by 3-(4,5dimethylthiazol-2-yl)-2,5-diphenyltetrazolium bromide (MTT, Sigma) assay as described previously (21). Briefly, exponentially growing cells were seeded into 96-well culture plates at a density of 3,000 cells per well. Five wells were assigned to each experimental treatment. After attachment for $24 \mathrm{~h}$, cells were treated with serial concentrations of Tyrphostin AG1478 for $72 \mathrm{~h}$. Then, $20 \mu \mathrm{l}$ of MTT solution $(5 \mathrm{mg} / \mathrm{ml})$ was added to each well for $4 \mathrm{~h}$ of incubation. The reaction was stopped by removal of MTT, and $150 \mu 1$ DMSO was added into each well in order to dissolve the formazan crystals. Absorbance at $595 \mathrm{~nm}$ was recorded using a 96-well microplate reader (Bio-Rad).

Cell growth inhibition of Tyrphostin AG1478 was also assessed by cell counting using a haemocytometer after 2 , 4, 6 and 8 days of culture. All measurements were done in triplicate.

Clone formation assay. The cells were plated at a density of 300 cells/well on 6-well plates. After attachment for $24 \mathrm{~h}$, cells were treated, in triplicate, with serial doses of Tyrphostin AG1478 for 7 days. The culture medium was changed every 3 days. Then the cells were washed twice with PBS, and stained with Giemsa solution. The number of clones containing 50 cells or more was counted under a microscope.
All experiments were repeated twice. The data were expressed as mean $\pm \mathrm{SD}$.

Assessment of apoptosis. ApoDETECT ${ }^{\mathrm{Tm}}$ Annexin V-FITC Kit (Zymed Laboratories Inc., San Francisco, CA) and flow cytometry were used for apoptosis assessment according to the manufacturer's protocol. Briefly, after having harvested and washed in cold PBS, the cells were resuspended in $190 \mu \mathrm{l}$ of binding buffer (10 mM of HEPES/NaOH, $\mathrm{pH} 7.4$, $140 \mathrm{mM}$ of $\mathrm{NaCl}$, and $2.5 \mathrm{mM}$ of $\mathrm{CaCl}_{2}$ ), and $10 \mu \mathrm{l}$ of Annexin V-FITC was added. After staining at room temperature for $10 \mathrm{~min}$, cells were washed in binding buffer and resuspended in $190 \mu \mathrm{l}$ of binding buffer, and $10 \mu \mathrm{l}$ of $20 \mu \mathrm{g} / \mathrm{ml}$ PI stock solution was added. Then, cells were analyzed in a FACScan flow cytometer (Becton-Dickinson, Franklin Lakes, NJ).

Western blot analysis. The cells were rinsed twice with icecold PBS and lysed in lysis buffer [60 mmol/l Tris- $\mathrm{HCl}(\mathrm{pH}$ 6.8), 2\%SDS, $100 \mathrm{mmol} / 1 \mathrm{DTT}, 50 \mathrm{mmol} / \mathrm{l} \mathrm{NaF}, 1 \mathrm{mmol} / \mathrm{l}$ $\left.\mathrm{Na}_{3} \mathrm{VO}_{4}\right]$. Protein concentration was determined by the BioRad Protein assay kit (Bio-Rad, Hercules, CA). Aliquots of whole-cell lysate $(50 \mu \mathrm{g})$ were resolved on SDS-PAGE gels, and transferred electrophoretically to nitrocellulose membranes (Bio-Rad). Blots were probed with primary antibodies against EGFR (sc-03; Santa Cruz Biotechnology, Santa Cruz, CA), Phospho-EGFR (P-Tyr1068; Cell Signaling Technology, Beverly, MA), AKT/P-AKT (P-Ser473; Cell Signaling Technology), or ERK/P-ERK (Santa Cruz Biotechnology) according to the manufacturer's recommendations. After washing, blots were incubated with a 1:5,000 dilution of horseradish peroxidase-linked secondary antibody (Promega). Antigen-antibody complexes were detected by using Enhanced Chemiluminescence reagent according to the manufacturer's instruction (Amersham Pharmacia Biotech, Buckinghamshire, UK).

Measurement of telomerase activity. Telomerase activity was measured by the Telo TAGGG Telomerase PCR ELISA ${ }^{\text {PLus }}$ kit (Roche Molecular Biochemicals), according to the manufacturer's instructions. Briefly, after harvesting and counting, aliquots of $2 \times 10^{5}$ cells were washed twice in PBS, and resuspended in $200 \mu \mathrm{l}$ of lysis buffer and kept on ice for $30 \mathrm{~min}$. Lysates were then assayed using the Bio-Rad Protein Assay Kit (Bio-Rad) for the determination of protein concentration. In order to perform the telomeric repeat amplification protocol (TRAP reaction), $1 \mu 1$ cell extract (corresponding to $1 \times 10^{3}$ cell equivalents) was used for PCR. The telomerase activity in the PCR products was quantified according to the manufacturer's instructions.

PCR analysis of hTERT expression. Expression level of hTERT mRNA was analyzed by semi-quantitative reverse transcription (RT)-PCR. Total cellular RNA was isolated using TRIzol reagent (Invitrogen) as described by the manufacturer. RNA was reverse transcribed using ThermoScript RT reverse transcriptase, random hexamers, and other kit reagents (ThermoScript ${ }^{\mathrm{TM}}$ RT-PCR System, Life Technologies), followed by PCR using hTERT forward primer 5'-tgcgtttggtggatgatttcttgt-3' and reverse primer 5'-ccgg 
A

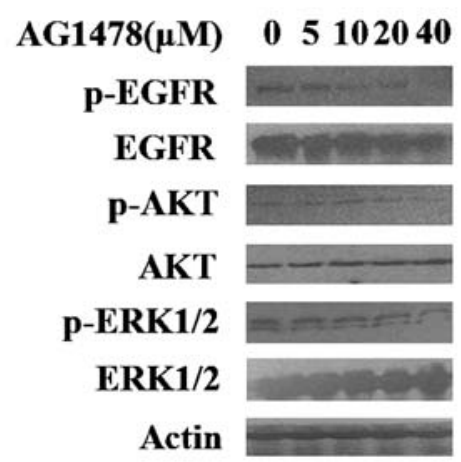

B2

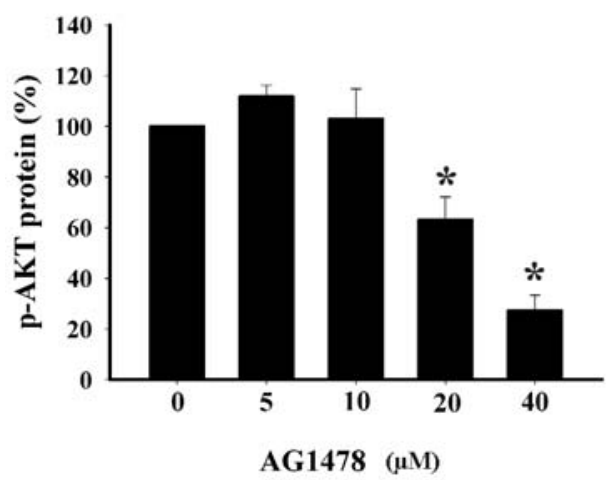

B1

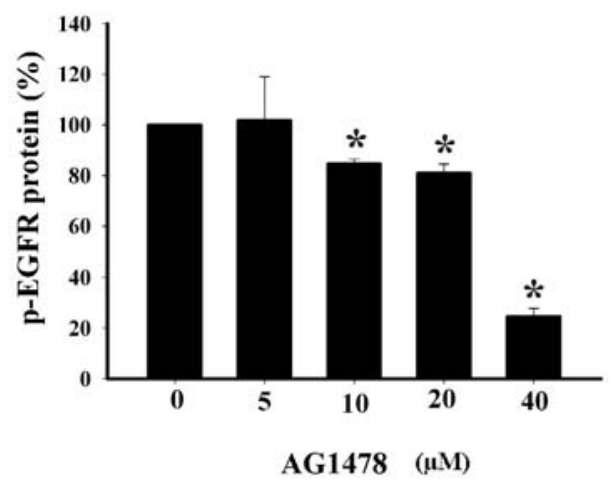

B3

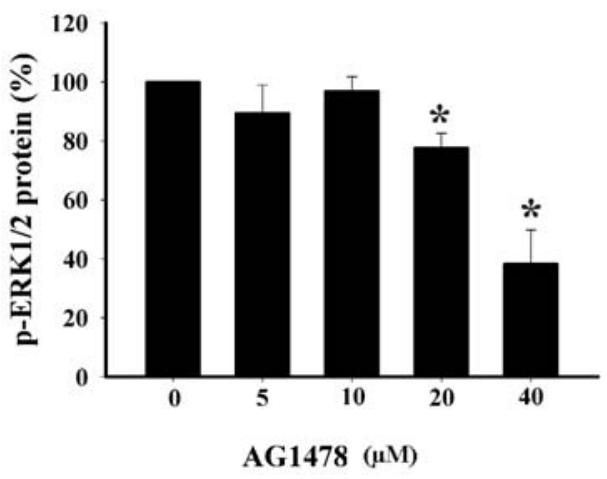

Figure 1. Effect of Tyrphostin AG1478 on epidermal growth factor receptor (EGFR) signaling. Exponentially growing cells MDA-MB-231 were cultured in serum-free medium for $24 \mathrm{~h}$, then exposed to various concentrations of AG1478 at 5, 10, 20, $40 \mu \mathrm{M}$ for $4 \mathrm{~h}$ of treatment, followed by $100 \mathrm{ng} / \mathrm{ml} \mathrm{EGF}$ treatment for $30 \mathrm{~min}$. DMSO (0.1\%) was used as a control. (A) Western blot analysis using antibodies against total EGFR, p-EGFR, AKT, p-AKT, ERK1/2 and p-ERK1/2. The actin serves as a loading control. Similar experiments were repeated at least twice. (B) Relative activated level of EGFR (B1), AKT (B2) and ERK1/2 (B3). For quantification, the intensity of each band was evaluated by densitometry using the quantity-one image analysis software (Bio-Rad). The relative protein value of p-EGFR, $\mathrm{p}$-AKT or p-ERK1/2 is presented as a ratio of the p-EGFR, p-AKT or p-ERK1/2 signal divided by the corresponding total EGFR, AKT or ERK1/2 signal, respectively. " $\mathrm{p}<0.01$ vs. control (no treatment).

gcatagctggagtagtcg-3' to amplify a 263-bp fragment of hTERT. Linear amplification cycles were determined as described elsewhere (22). The PCR program initially started with a $94^{\circ} \mathrm{C}$ denaturation for $5 \mathrm{~min}$, followed by 31 cycles of $94^{\circ} \mathrm{C}$ for $30 \mathrm{sec}, 60^{\circ} \mathrm{C}$ for $30 \mathrm{sec}$, and $72^{\circ} \mathrm{C}$ for $30 \mathrm{sec}$. The housekeeping $\beta$-actin transcript, used as internal standard, was amplified to generate a 541-bp fraction in parallel by 25 cycles with $\beta$-actin sense (5'-gtggggcgcccaggcacca-3') and antisense (5'-ctccttaatgtcacgcacgatttc-3') primers. PCR products were subjected to electrophoresis in $8 \%$ polyacrylamide gel and stained with ethidium bromide. The intensity of each band was evaluated by densitometry using quantity-one image analysis software (Bio-Rad). The hTERT mRNA values are presented as a ratio of the hTERT signal divided by the $B$-actin signal.

Cell invasion assay. A boyden chamber invasion assay was used to quantify cell invasion (21). Briefly, polycarbonate filters with $8-\mu \mathrm{m}$ pores (Millipore) were coated with matrigel (BD Biosciences). Cells $\left(2 \times 10^{5}\right)$ were seeded into the upper chambers and cultured in the presence of serial concentrations of AG1478 for $12 \mathrm{~h}$ at $37^{\circ} \mathrm{C}$. After mechanically removing cells on the upper surface of membranes, the filters were fixed in methanol and stained with hematoxylin and eosin. Then the cells having migrated onto the lower surface were counted manually under a light microscope, with $\mathrm{x} 200$ magnification. Each experiment was repeated twice, and 5 microscopic fields from each filter were counted. Results were expressed as the mean number of cells counted in each field \pm standard deviation.

\section{Results}

Effect of Tyrphostin AG1478 on EGFR signaling. To determine the effect of Tyrphostin AG1478 on EGFR signaling, phosphorylation levels of EGFR, ERK1/2 and AKT were evaluated by Western blotting. As shown in Fig. 1, treatment of cells with AG1478 demonstrated a pronounced reduction in phosphorylation of EGFR (p-EGFR) in MDA-MB-231 cells. AG1478 treatment inhibited the activity of ERK1/2 and AKT, downstream key regulators of EGFR signaling, in a dose-dependent manner. These results suggest that AG1478 can effectively inhibit EGFR signaling.

Effect of Tyrphostin AG1478 on the proliferation of breast cancer cells. Three proliferation analyses, MTT, cell counting, and clone formation assay, were used to assess the proliferative ability of breast cancer cells treated with Tyrphostin AG1478. MTT assay showed that AG1478 inhibited cellular proliferation of breast cancer cells MCF-7 and MDA-MB-231 in a dose-dependent manner (Fig. 2A). After 3 days of treatment of MCF-7 cells, AG1478 of 10, 20 and $40 \mu \mathrm{M}$ inhibited the cellular growth by $9.5,22.2$ and $50.8 \%$, respectively, relative to the control cells. In MDA-MB-231 cells, AG1478 of 10,20 and $40 \mu \mathrm{M}$ suppressed the cellular growth by $8.8,25.8$ and $57.6 \%$, respectively. 
A

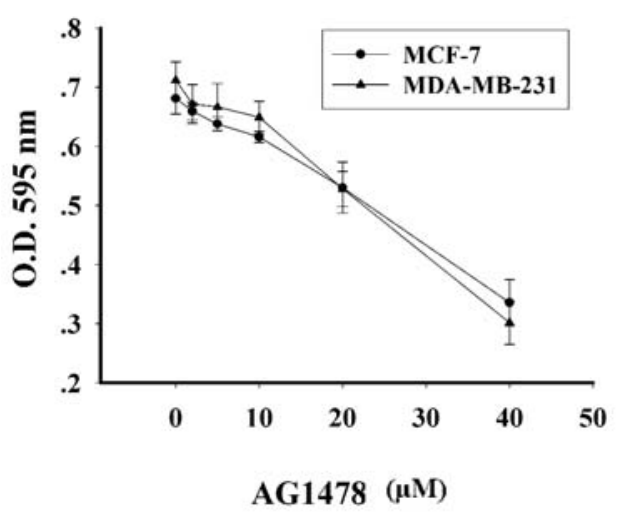

B2

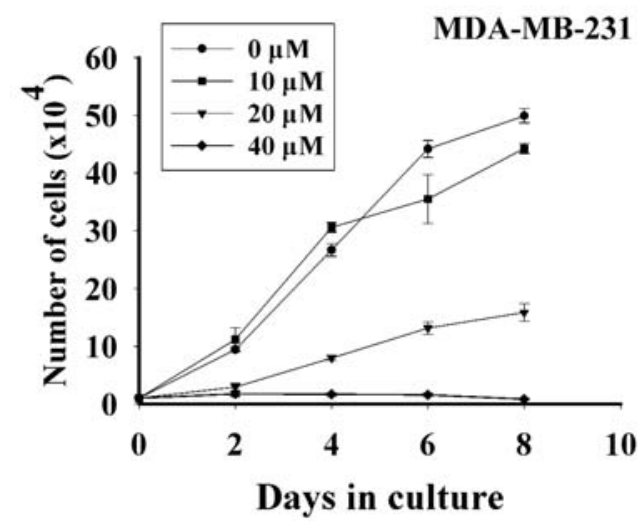

B1

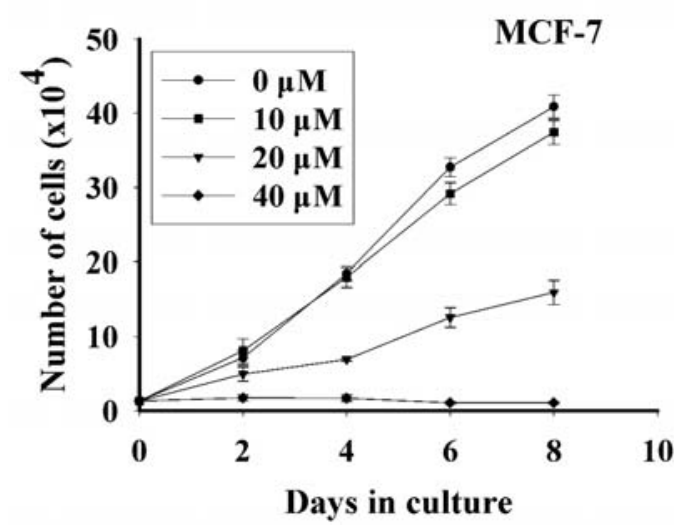

C

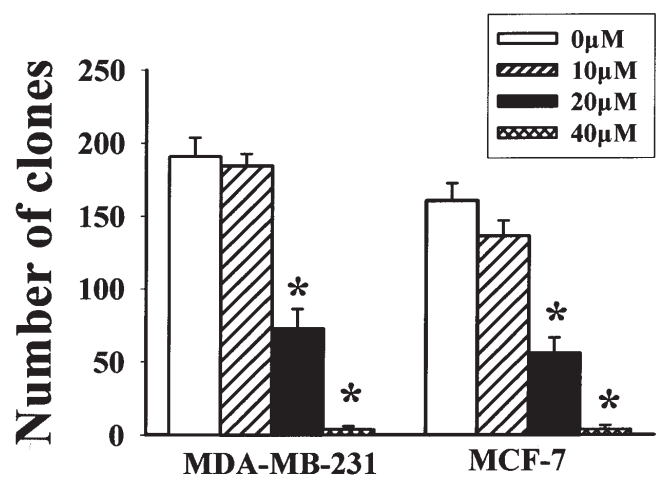

Figure 2. Effect of Tyrphostin AG1478 on the proliferation of human breast cancer cells. (A) MTT assay to examine the antiproliferative effects of AG1478 on breast cancer cells MCF-7 and MDA-MB-231. Cells (3,000 cells/well) were seeded into 96-well plates. After attachment for $24 \mathrm{~h}$, cells were treated with serial concentrations of Tyrphostin AG1478 $(2.5,5,10,20,40 \mu \mathrm{M})$ for $72 \mathrm{~h}$. Five wells were assigned to each experimental treatment. Experiments were repeated three times, data are presented as means $\pm \mathrm{SD}$ (vertical bars). (B) Cell counting to assess the antiproliferative effects of AG1478 on breast cancer cells MCF-7 (B1) and MDA-MB-231 (B2). Cells (1x104/well) were seeded on 24-well plates. After attachment for $24 \mathrm{~h}$, cells were treated, in triplicate, with serial doses of Tyrphostin AG1478. Proliferation was evaluated by cell counting using a haemocytometer after 2, 4, 6 and 8 days of culture. Experiments were repeated three times, data are presented as means \pm SD (vertical bars). (C) Clone formation assay to examine the antiproliferative effects of AG1478. Cells (300 cells/well) were plated on 6-well plates. After attachment for $24 \mathrm{~h}$, cells were treated, in triplicate, with serial doses of Tyrphostin AG1478 for 7 days at $37^{\circ} \mathrm{C}$. Culture medium was changed every three days. Finally, the cells were stained with Giemsa solution. The number of clones containing 50 cells or more was counted under a microscope. The values shown are the mean $\pm \mathrm{SD}$ of three independent experiments. ${ }^{*} \mathrm{p}<0.01$ vs. control (no treatment).

A1
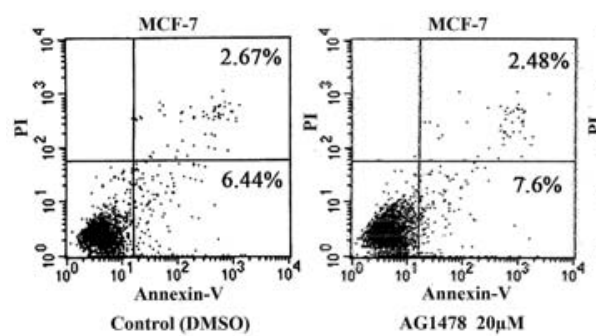

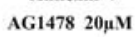

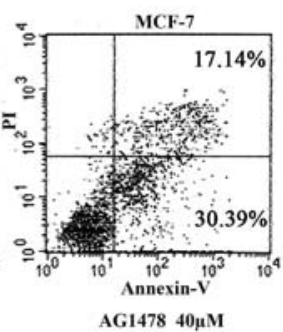

B

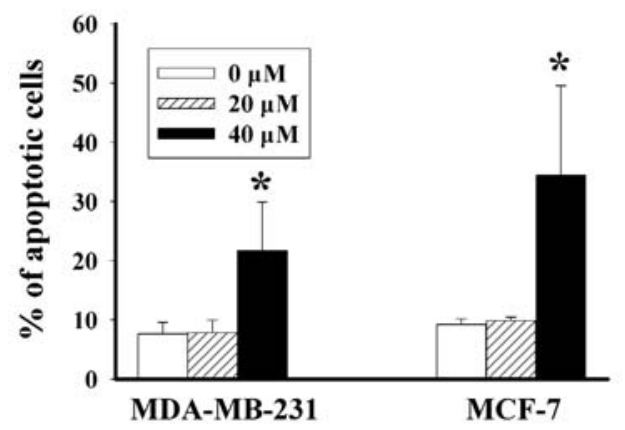

A2
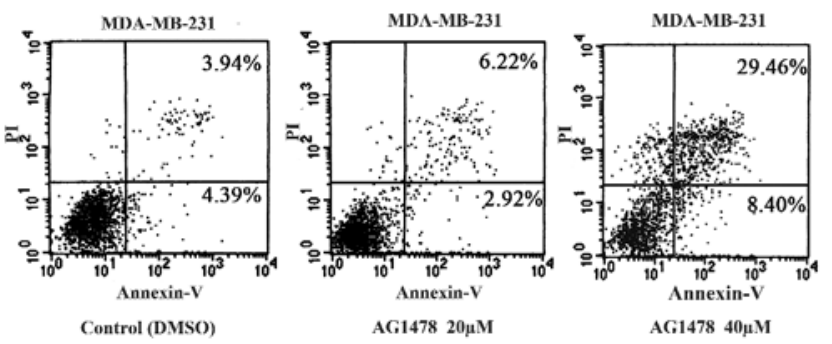

Figure 3. Effect of Tyrphostin AG1478 on apoptosis of tumor cells. (A) Flow cytometry analysis of apoptosis using Annexin $\mathrm{V}$ as described in Materials and methods. MCF-7 (A1) or MDA-MB-231 (A2) cells were exposed to Tyrphostin AG1478 for $48 \mathrm{~h}$. (B) The percentage of apoptotic cells was determined by quantifying the Annexin V-positive cell population. Data are presented as mean \pm SD of three independent experiments. "p $<0.05$ vs. control (no treatment).

Cell counting assay also demonstrated the anti-proliferative effects of Tyrphostin AG1478 on MDA-MB-231 and MCF-7 cells in a dose-dependent manner (Fig. 2B). In MCF-7 


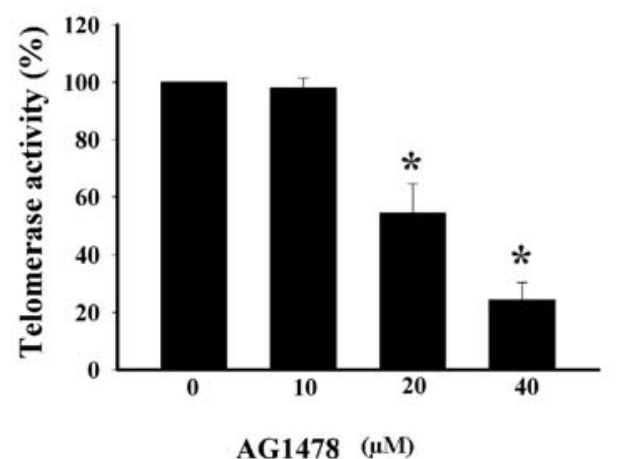

Figure 4. Effect of Tyrphostin AG1478 on telomerase activity. Cells were treated with AG1478 for $72 \mathrm{~h}$, and telomerase activity was examined by the Telo TAGGG Telomerase PCR ELISA ${ }^{\text {PLUS }}$ kit. ${ }^{*} \mathrm{p}<0.01$ vs. control (no treatment).

A

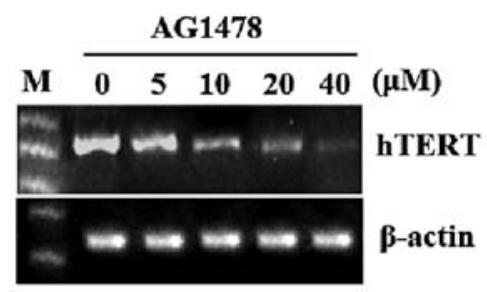

B

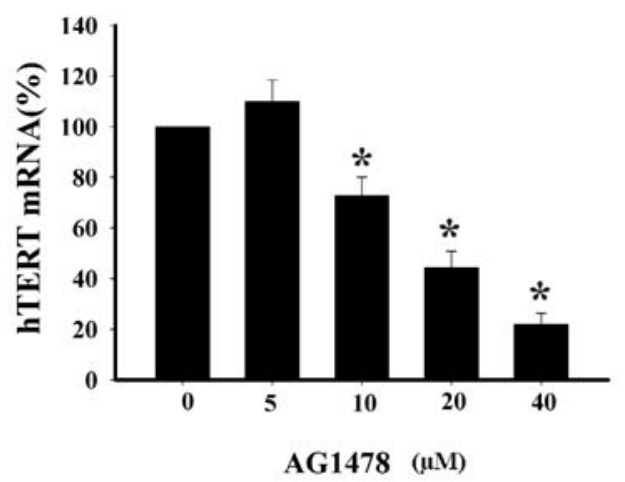

Figure 5. Effect of Tyrphostin AG1478 on hTERT mRNA expression. (A) Semi-quantitative RT-PCR to examine the hTERT mRNA expression. Cells were treated with AG1478 for $72 \mathrm{~h}$. (B) Relative hTERT mRNA expression level after AG1478 treatment. The hTERT mRNA values are presented as a ratio of the hTERT's signal divided by the $\beta$-actin signal. ${ }^{*} \mathrm{p}<0.01$ vs. control (no treatment).

cells, AG1478 of 10, 20 and $40 \mu \mathrm{M}$ inhibited the cellular growth by $8.5,61.6$ and $98.1 \%$ respectively on the 8 th day, relative to the control cells. While in MDA-MB-231 cells, it was $11.3,68.3$ and $98.3 \%$, respectively.

To further determine the effects of Tyrphostin AG1478 on cellular growth of breast cancer cells, clone-formation assay was performed in MDA-MB-231 and MCF-7 cells. As shown in Fig. 2C, the clone formation of MCF-7 and MDA-MB-231 cells was suppressed by AG1478 in a dosedependent manner. In MCF-7 cells, the clone efficiency was $53.7,45.3,18.7$ and $1.3 \%$ in control cells, 10, 20 and $40 \mu \mathrm{M}$ AG1478 treated cells, respectively. In MDA-MB-231 cells, it was $63.7,61.3,24.3$ and $1.3 \%$, respectively.

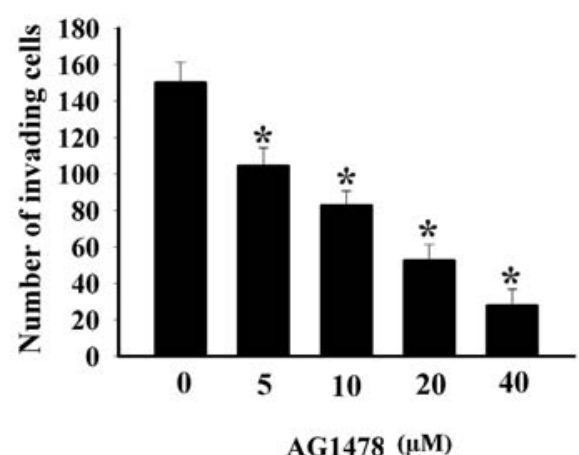

Figure 6. Effect of Tyrphostin AG1478 on invasion of tumor cells. A boyden chamber invasion assay was used to quantify cell invasion. Cells $\left(2 \times 10^{5}\right)$ were seeded into the upper chambers and cultured in the presence of serial concentrations of AG1478 for $12 \mathrm{~h}$ at $37^{\circ} \mathrm{C}$. Then the cells having migrated onto the lower surface were counted manually under a light microscope, with $\times 200$ magnification. Data are presented as the mean number of cells counted in each field \pm SD of three independent experiments. ${ }^{*} \mathrm{p}<0.01$ vs. control (no treatment).

Effect of Tyrphostin AG1478 on apoptosis. The effect of Tyrphostin AG1478 on apoptosis was evaluated by ApoDETECT Annexin V-FITC Kit, which detects early stages of apoptosis (i.e., conformational changes in the plasma membrane). Apoptotic cells can be recognized and distinguished from necrotic cells using flow cytometry (FACScan; Becton-Dickinson Systems) after double staining by Annexin V-FITC and PI. As shown in Fig. 3, $20 \mu \mathrm{M}$ AG1478 did not induce significant apoptosis in either MDA-MB-231 or MCF-7 cells, compared with corresponding control cells ( $\mathrm{p}>0.05)$. However, $40 \mu \mathrm{M}$ AG1478 induce significant apoptosis in both MDA-MB-231 and MCF-7 cells, compared with corresponding control cells $(p<0.05)$. These results suggest that the EGFR inhibitor AG 1478 can promote cellular apoptotic response in breast cancer cells.

Effects of Tyrphostin AG1478 on telomerase activity. To investigate whether Tyrphostin AG1478 could inhibit telomerase activity in breast cancer cells, we examined telomerase activity of MDA-MB-231 cells using the Telo TAGGG Telomerase PCR ELISA ${ }^{\text {PLUS }}$ kit. Our results showed that Tyrphostin AG1478 suppressed telomerase activity in a dose-dependent manner (Fig. 4). In an attempt to elucidate the mechanism of AG1478 in suppressing telomerase activity, we evaluated the transcriptional level of hTERT. Semiquantitative RT-PCR assay showed that Tyrphostin AG1478 down-regulated hTERT mRNA in a dose-dependent manner (Fig. 5). These results suggest that Tyrphostin AG1478 downregulated telomerase activity of breast cancer cells probably by inhibiting the expression of hTERT mRNA.

Effect of AG1478 on invasion of breast cancer cells. To determine whether Tyrphostin AG1478 could affect cell invasion, we performed in vitro invasion assays in MDA-MB-231 cells. Fig. 6 showed that Tyrphostin AG1478 suppressed cell invasion in a dose-dependent manner. In an attempt to elucidate the mechanism of AG1478 in suppressing cellular invasion, the protein expressions of tumor metastasis- 
A

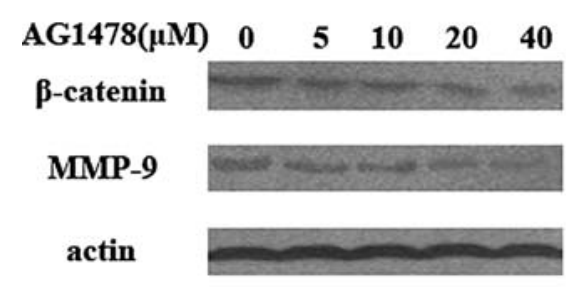

B

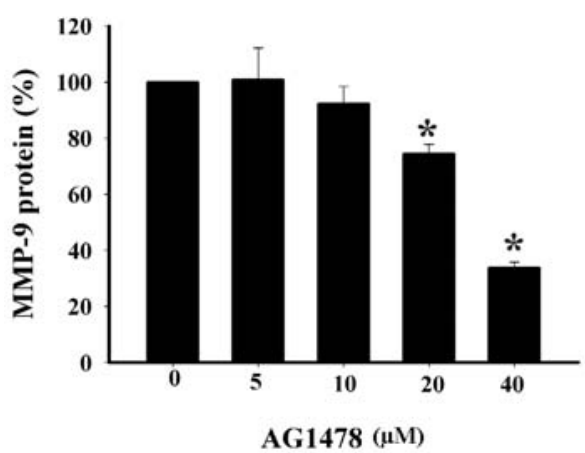

Figure 7. Effect of Tyrphostin AG1478 on MMP-9 expression. (A) Western blot analysis using antibodies against MMP-9 and B-catenin. The actin serves as a loading control. Similar experiments were repeated at least twice. (B) Relative MMP-9 protein level. For quantification, the intensity of each band was evaluated by densitometry using the quantity-one image analysis software (Bio-Rad). The relative protein value of MMP-9 is presented as a ratio of the MMP-9 signal divided by the corresponding actin. ${ }^{*} \mathrm{p}<0.01$ vs. control (no treatment).

associated genes $\beta$-catenin and MMP-9 were assessed in the very invasive MDA-MB-231 cells. Western blotting showed that the expression of MMP-9, but not $\beta$-catenin, was downregulated by AG1478 in a dose-dependent manner (Fig. 7). This result indicated that the inhibition effect of AG1478 on cellular invasion was associated with MMP-9 down-regulation.

\section{Discussion}

Breast carcinoma is the most common malignancy in women and represents the second leading cause of cancer death among women (just after lung cancer). The incidence of breast cancer in Asian countries and around the world has been increasing, partly due to intensive screening and better diagnostic tools. Despite aggressive treatment by surgery, radiotherapy and chemotherapy, the prognosis of breast cancer remains grim. The recent progress of molecular targeting drugs, like trastuzumab, has shown a great deal of promise, but searching for novel agents will be necessary for successful therapies of breast cancer.

In this study, for the first time we report that Tyrphostin AG1478 blocks proliferation and invasion of breast cancer cells. The quinazoline derivative AG1478 [4-(3-chloroanilino)-6, 7-dimethoxyquinazoline] as a competitive inhibitor of the ATP binding site in the kinase domain, is a highly potent and specific reversible tyrosine kinase inhibitor of the EGFR (23). There is increasing evidence to suggest that AG1478 has anti-tumor activity. In in vitro studies, AG1478 showed significant anti-proliferative effects in glioblastoma (24), leiomyoma (25), colorectal carcinoma (26) and nasopharyngeal carcinoma cells (15). In tumour xenograft models, AG1478 inhibits the growth of A431 tumours (17) and human glioblastomas $(17,18)$. Moreover, AG1478 also sensitizes these tumours to the cytotoxic action of cisplatin and temozolomide or the monoclonal antibody mAb 806, an anti-EGFR antibody $(18,20,27)$. In MDA-MB-231 and MCF-7 breast cancer cells, we observed that AG1478 could effectively inhibit the activation of EGFR and its downstream ERK1/2 and AKT signaling pathways, and had a similar anti-proliferative activity in these two cell lines, although they express EGFR at different levels. Similarly, preclinical studies, in vitro and in vivo, have demonstrated that the anti-proliferative activity of EGFR tyrosine kinase inhibitor ZD1839 is not directly related to EGFR expression levels (28). To further investigate the probable mechanism of anti-proliferative efficacy of AG1478, we examined the effect of AG1478 on apoptosis and telomerase activity of breast cancer cells. Our results showed that AG1478 could promote cell apoptosis in MDA-MB-231 and MCF-7 cells. It has been reported that AG1478 effectively induced apoptosis in colorectal carcinoma cells (26). EGFR inhibitor AG1478 and ErbB2 kinase inhibitor AG879 synergized the induction of apoptosis in human colon carcinoma cells (29). It has been suggested that EGFR-dependent MAPK activation affects the balance of members of the Bcl-2 family of proteins that control apoptosis susceptibility, therefore, targeting the EGFR in cancer could induce apoptosis (30). Activation of telomerase, which stabilizes the telomere length of chromosomes, is crucial for the development or progression of malignant tumors. This led us to question whether EGFR TKI AG1478 suppressed the proliferative activity of breast cancer cells by inhibiting telomerase activity. It has been reported that blockade of EGFR by AG1478 or antisenseEGFR approach could inhibit telomerase activity of human cutaneous squamous cell carcinoma cells or glioblastoma cells $(31,32)$. Additionally, a research group showed that EGF activated telomerase through Ets-mediated transactivation of TERT via MAP kinase signaling pathway (33). Telomerase may affect proliferation of epithelial cells not only by stabilizing telomeres, but also by increasing the expression of growth-promoting genes, such as EGFR and basic fibroblast growth factor (34). It is suggested that telomerase has a function in cell division (34). In agreement with these findings, we demonstrated that blockade of EGFR by AG1478 suppressed the telomerase activity and downregulated hTERT mRNA expression of MDA-MB-231cells, which may be another mechanism of AG1478 in tumor growth suppression.

Tumor cell migration and invasion is a critical factor for malignant tumor metastasis, which is a multiple processes and is regulated by many genes. EGF has been shown to stimulate the migration of both normal and tumor cells, including normal mammary epithelial cells and breast carcinoma cells $(10,13)$. In this study, we investigated the effect of AG1478 on cellular invasion of breast carcinoma cells. Boyden chamber assay showed that AG1478 effectively blocked the cell invasion of the highly metastatic cell line MDA-MB-231, in a dose-dependent manner. Consistent with our data, AG1478 inhibited the strong in vitro invasiveness of pancreatic carcinoma cells (35). Similarly, Reddy et al has demonstrated that blockade of MAPK activity by RG13022, a tyrosine kinase inhibitor of EGFR, inhibited cell 
invasion of MDA-MB-231 and T47D breast cancer cells (35). It has been suggested that PLC $\gamma$, an EGFR downstream signaling molecular, is involved in EGF-induced motility in a variety of cells including stromal and endothelial cells (37). Our data and others indicate that PI3K pathway and MAP kinase pathway may also be involved in the EGFR-mediated modulation of cell invasion $(35,36)$. The metastatic process requires the degradation of the extracellular matrix both at the primary tumor site and at the secondary colonization site. This degradation process is dependent on the activity of specific endopeptidases, the matrix metalloproteinases (MMPs) (38). MMP9 expression has been related to the invasive property of a variety of cancers including breast carcinoma $(39,40)$. Our data (not shown) showed that MDAMB-231, a highly metastatic breast cancer cell line, expresses higher level of MMP-9 than MCF-7, a relatively low metastatic breast cancer cell line. AG1478 significantly suppressed the MMP-9 expression in MDA-MB-231 cells. It has been reported that EGF and Amphiregulin (AR), a ligant of EGFR, could modulate invasion of breast cancer cells by increasing expression of the extracellular matrix metalloproteinase inducer (EMMPRIN) and MMP-9 (41). They also demon-strated that blockade of MAPK activity could significantly reduce EGF-induced cell proliferation, MMP-9 induction and invasion of SKBR-3 breast cancer cells (41). MMP-9 down-regulation may be one of the mechanisms by which AG1478 induced invasion suppression.

In summary, this study demonstrated that AG1478 significantly inhibited the proliferative and invasive capacity of human breast cancer cells. Tyrphostin AG1478 may be a potential EGFR-targeted therapeutic agent for breast cancer.

\section{Acknowledgements}

This study was supported by the National Natural Sciences Foundation of China (30670805 and 30770829).

\section{References}

1. Sibilia M, Kroismayr R, Lichtenberger BM, Natarajan A, Hecking $M$ and Holcmann M: The epidermal growth factor receptor: from development to tumorigenesis. Differentiation 75: 770-787, 2007.

2. Press MF and Lenz HJ: EGFR, HER2 and VEGF pathways: validated targets for cancer treatment. Drugs 67: 2045-2075, 2007.

3. Laskin JJ and Sandler AB: Epidermal growth factor receptor: a promising target in solid tumours. Cancer Treat Rev 30: 1-17, 2004.

4. Marshall J: Clinical implications of the mechanism of epidermal growth factor receptor inhibitors. Cancer 107: 1207$1218,2006$.

5. Pander J, Gelderblom H and Guchelaar HJ: Pharmacogenetics of EGFR and VEGF inhibition. Drug Discov Today 12: 1054-1060, 2007.

6. Harari PM, Allen GW and Bonner JA: Biology of interactions: antiepidermal growth factor receptor agents. J Clin Oncol 25: 4057-4065, 2007.

7. Harari PM: Anti-EGFR therapy update: clinical experience and adverse event insights. Oncology (Williston Park) 20 (Suppl. 2): 3-4, 2006.

8. Rocha-Lima CM, Soares HP, Raez LE and Singal R: EGFR targeting of solid tumors. Cancer Control 14: 295-304, 2007.

9. Kurokawa $\mathrm{H}$ and Arteaga CL: Inhibition of erbB receptor (HER) tyrosine kinases as a strategy to abrogate antiestrogen resistance in human breast cancer. Clin Cancer Res 7 (Suppl. 12): S4436-S4442, 2001.
10. Hynes NE and Lane HA: ErbB receptors and cancer: the complexity of targeted inhibitors. Nature Rev Cancer 5: 341-354, 2005.

11. Baselga J, Albanell J, Ruiz A, et al: Phase II and tumor pharmacodynamic study of gefitinib in patients with advanced breast cancer. J Clin Oncol 23: 5323-5333, 2005.

12. von Minckwitz G, Jonat W, Fasching P, et al: A multicentre phase II study on gefitinib in taxane- and anthracycline-pretreated metastatic breast cancer. Breast Cancer Res Treat 89: 165-172, 2005.

13. Emlet DR, Schwartz R, Brown KA, Pollice AA, Smith CA and Shackney SE: HER2 expression as a potential marker for response to therapy targeted to the EGFR. Br J Cancer 94: 1144-1153, 2006.

14. Lichtner RB, Menrad A, Sommer A, Klar U and Schneider MR: Signaling-inactive epidermal growth factor receptor/ligand complexes in intact carcinoma cells by quinazoline tyrosine kinase inhibitors. Cancer Res 61: 5790-5795, 2001.

15. Zhu XF, Liu ZC, Xie BF, et al: EGFR tyrosine kinase inhibitor AG1478 inhibits cell proliferation and arrests cell cycle in nasopharyngeal carcinoma cells. Cancer Lett 169: 27-32, 2001.

16. Busse D, Doughty RS, Ramsey TT, et al: Reversible G1 arrest induced by inhibition of the epidermal growth factor receptor tyrosine kinase requires up-regulation of p27KIP1 independent of MAPK activity. J Biol Chem 275: 6987-6995, 2000.

17. Nagane N, Levitzki A, Gazit A, Cavanee WK and Huang HJ: Drug resistance of human glioblastoma cells conferred by a tumour specific mutant epidermal growth factor receptor through modulation of Bcl-XL and caspase 3-like proteases. Proc Natl Acad Sci USA 95: 5724-5729, 1998.

18. Lei W, Mayotte EJ and Levitt LM: Enhancement of chemosensitivity and programmed cell death by tyrosine kinase inhibitors correlates with EGFR expression in non-small cell lung cancer cells. Anticancer Res 19: 221-228, 1999.

19. Johns TG, Luwor RB, Murone C, et al: Antitumour efficacy of cytotoxic drugs and the monoclonal antibody 806 is enhanced by the EGF receptor inhibitor AG1478. Proc Natl Acad Sci USA 100: 15871-15876, 2003.

20. He HY, Fang WG, Zheng J, et al: Mechanisms of mitogenactivated protein kinase phosphatase- 5 regulation growth and invasion of a human prostate cancer cell line. Natl Med J China 83: $1812-1818,2003$.

21. Ogretmen B, McCauley MD and Safa AR: Molecular mechanisms of loss of beta 2-microglobulin expression in drug-resistant breast cancer sublines and its involvement in drug resistance. Biochemistry 37: 11679-11691, 1998.

22. Papageorgio C and Perry MC: Epidermal growth factor receptor-targeted therapy for pancreatic cancer. Cancer Invest 25: 647-657, 2007.

23. Ellis AG, Doherty MM, Walker F, et al: Preclinical analysis of the analinoquinazoline AG1478, a specific small molecule inhibitor of EGF receptor tyrosine kinase. Biochemical Pharmacol 71: 1422-1434, 2006.

24. Shushan A, Rojansky N, Laufer N, et al: The AG1478 tyrosine kinase inhibitor is an effective suppressor of leiomyoma cell growth. Hum Reprod 19: 1957-1967, 2004.

25. Partik G, Hochegger K, Schörkhuber M and Marian B: Inhibition of epidermal -growth-factor-receptor-dependent signalling by tyrphostins A25 and AG1478 blocks growth and induces apoptosis in colorectal tumour cells in vitro. J Cancer Res Clin Oncol 125: 379-388, 1999.

26. Perera RM, Narita Y, Furnari FB, et al: Treatment of human tumor xenografts with monoclonal antibody 806 in combination with a prototypical epidermal growth factor receptor-specific antibody generates enhanced antitumor activity. Clin Cancer Res 11: 6390-6399, 2005

27. Nakamura H, Takamori S, Fujii T, et al: Cooperative cellgrowth inhibition by combination treatment with ZD1839 (Iressa) and trastuzumab (Herceptin) in non-small-cell lung cancer. Cancer Lett 230: 33-46, 2005.

28. Zhou Y and Brattain MG: Synergy of epidermal growth factor receptor kinase inhibitor AG1478 and ErbB2 kinase inhibitor AG879 in human colon carcinoma cells is associated with induction of apoptosis. Cancer Res 65: 5848-5856, 2005.

29. Kari C, Chan TO, Rocha de Quadros M and Rodeck U: Targeting the epidermal growth factor receptor in cancer: apoptosis takes center stage. Cancer Res 63: 1-5, 2003.

30. Budiyanto A, Bito T, Kunisada M, Ashida M, Ichihashi M and Ueda M: Inhibition of the epidermal growth factor receptor suppresses telomerase activity in HSC-1 human cutaneous squamous cell carcinoma cells. J Invest Dermatol 121: 1088-1094, 2003. 
31. Tian XX, Pang JC, Zheng J, et al: Antisense epidermal growth factor receptor RNA transfection in human glioblastoma cells down-regulates telomerase activity and telomere length. $\mathrm{Br} \mathrm{J}$ Cancer 86: 1328-1332, 2002.

32. Maida Y, Kyo S, Kanaya T, et al: Direct activation of telomerase by EGF through Ets-mediated transactivation of TERT via MAP kinase signaling pathway. Oncogene 21: 4071-4079, 2002.

33. Smith LL, Coller HA and Roberts JM: Telomerase modulates expression of growth-controlling genes and enhances cell proliferation. Nat Cell Biol 5: 474-479, 2003.

34. Tan X, Egami H, Abe M, Nozawa F, Hirota M and Ogawa M: Involvement of MMP-7 in invasion of pancreatic cancer cells through activation of the EGFR mediated MEK-ERK signal transduction pathway. J Clin Pathol 58: 1242-1248, 2005.

35. Reddy KB, Mangold GL, Tandon AK, et al: Inhibition of breast cancer cell growth in vitro by a tyrosine kinase inhibitor. Cancer Res 52: 3636-3641,1992.

36. Wells A, Ware MF, Allen FD and Lauffenburger DA: Shaping up for shipping out: PLCgamma signaling of morphology changes in EGF stimulated fibroblast migration. Cell Motil Cytoskeleton 44: 227-233, 1999.
37. Kanekura T, Chen X and Kanzaki T: Basigin (CD147) is expressed on melanoma cells and induces tumor cell invasion by stimulating production of matrix metalloproteinases by fibroblasts. Int J Cancer 99: 520-528, 2002.

38. Zhang YG, Du J, Tian XX, Zhong YF and Fang WG: Expression of E-cadherin, beta-catenin, cathepsin D, gelatinases and their inhibitors in invasive ductal breast carcinomas. Chin Med J 120: 1597-1605, 2007.

39. Ellerbroek SM, Halbleib JM, Benavidez M, et al: Phosphatidylinositol 3-kinase activity in epidermal growth factor-stimulated matrix metalloproteinase-9 production and cell surface association. Cancer Res 61: 1855-1861, 2001.

40. Menashi S, Serova M, Ma L, Vignot S, Mourah S and Calvo F: Regulation of extracellular matrix metalloproteinase inducer and matrix metalloproteinase expression by amphiregulin in transformed human breast epithelial cells. Cancer Res 63: 7575-7580, 2003

41. Reddy KB, Krueger JS, Kondapaka SB and Diglio CA: Mitogenactivated protein kinase (MAPK) regulates the expression of progelatinase B (MMP-9) in breast epithelial cells. Int J Cancer 82: 268-273, 1999. 